\title{
A REVIEW ON DEVELOPMENT AND VALIDATION OF STABILITY INDICATING HPLC METHODS FOR ANALYSIS OF ACIDIC DRUGS
}

\author{
DEVYANI M. RODE, NUTAN N. RAO*
}

*Department of Pharmaceutical Chemistry and Quality Assurance, Oriental College of Pharmacy, Sector 2, Sanpada West, Navi Mumbai, Maharashtra, India

Email: nutan.rao@ocp.edu.in

Received: 15 Apr 2019, Revised and Accepted: 13 Jun 2019

\section{ABSTRACT}

High-performance liquid chromatography is one of the fastest, safest and precise technology used for determination and separation of pharmaceutical drugs, impurities and biological samples. High-performance liquid chromatography is versatile and it takes less time for quantification of drugs as compared to old liquid chromatography techniques. This article reviews stability indicating HPLC method developed and validated for acidic drugs and their degradation studies.

Keywords: High-performance liquid chromatography, Acidic drugs, Stability indicating method development and validation

(C) 2019 The Authors. Published by Innovare Academic Sciences Pvt Ltd. This is an open access article under the CC BY license (http://creativecommons.org/licenses/by/4.0/)

DOI: http://dx.doi.org/10.22159/ijcpr.2019v11i4.34939

\section{INTRODUCTION}

High-performance liquid chromatography is also known as highpressure liquid chromatography is an advanced analytical technique that is used for separation, determination, identification, and quantification of active drugs, proteins and impurities [1-2]. HPLC is a type of column chromatography. In column chromatography, the sample is passed through a column with the help of gravity which takes more time for analysis of drugs but in HPLC sample is passed through the column under high pressure up to 400 atmospheres so that fast separation takes place [1-2]. HPLC consist of mobile phase reservoir system, pump, column and detector which records and shows separation result. In HPLC, the pump moves the mobile phase and sample towards the column. Column is the most important part of the HPLC system. In HPLC, column is made up of adsorbent material and most of the columns are made by using silica gel. The elution of the sample depends on the interaction of the sample with the column material and it also depends on the mobile phase. Mobile phase mainly consists of organic liquids such as methanol, acetonitrile and also consists of water. Sometimes buffers are also used as mobile phase. There are two types of elution: (1) HPLC isocratic elution: in which composition of the mobile phase is same during the whole analysis and (2) Gradient elution in which composition is changed during the analysis or separation of sample.

\section{Instrumentation}

The instrumentation of HPLC consists of mobile reservoir phase, pump, column, detector and recorder as shown in fig. 1.

\section{Mobile phase reservoir}

In HPLC, contents of the mobile phase are stored in a glass container. The mobile phase is a mixture of organic and aqueous liquids in a different proportion which mainly depends on the nature and solubility of drugs [1-7].

\section{Pump}

Pump pushes or moves mobile phase and sample to the column under high pressure up to 4000atmospheres. Pump pressure depends on column dimension, particle size, flow rate and composition of mobile phase [1-7].

\section{Column}

Column is the most important part of HPLC. Column is made of stainless steel and is $50 \mathrm{~mm}$ to $300 \mathrm{~mm}$ long. They are generally loaded with the stationary phase or adsorbent and the inner diameter of the column is $<2 \mu \mathrm{m}$ to $5 \mu \mathrm{m}$ [1-7].

\section{Detector}

Detector detects the retention time of the sample. Detector is situated after the column so; it collects the sample and detects its retention time. Different types of detectors used are UV, fluorescence, IR, MASS detectors [1-7].

\section{Recorder}

Recorder records the peak, peak area, tailing factor, theoretical plate of the sample [1-7].

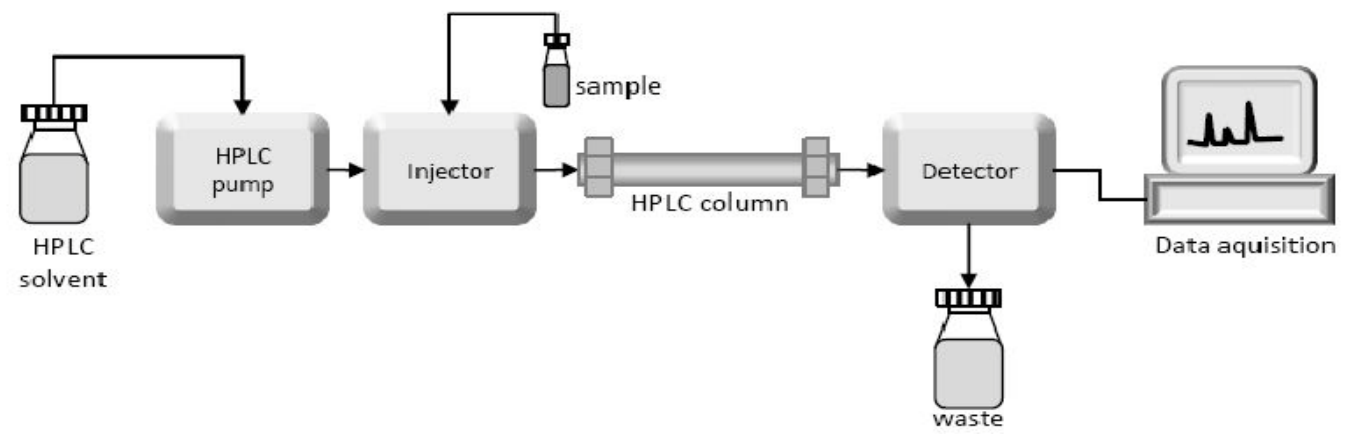

Fig. 1: Instrumentation of HPLC 


\section{Introduction of acidic drugs}

Most of the drugs used in medicines are either weak acids, weak bases or both weak acids and weak bases. pKa value of drugs gives information about the nature of drug whether it is acidic or basic in nature. $\mathrm{pKa}$ value gives information about the strength of acids and bases and also indicates the at which $\mathrm{pH}$ drug gets $50 \%$ ionized. The acidity of a drug depends on the functional group which is present in their structure. Functional groups such as carboxylic acid, amine, and phenolic groups are responsible for the acidic nature of drug. A number of commonly used drugs are carboxylic acid derivatives. These include NSAID-Aspirin, anticancer agent-Methotrexate, antibacterial agent-Amoxicillin, and the diuretic-Furosemide.

Amoxicillin is an antibacterial agent that belongs to the penicillin class. In amoxicillin, the $\beta$ lactam ring is present and all penicillins are organic acids having various electron donor groups in their structure. In amoxicillin structure, carboxylate (COO-) and amino $\mathrm{NH}_{2}$ groups are electron donor and these groups are responsible for the acidic nature of amoxicillin (fig. 2) [3].

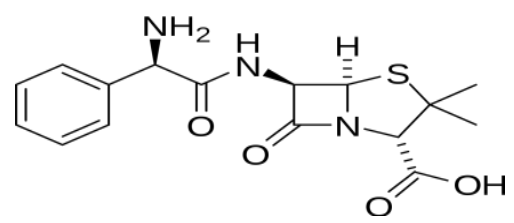

Fig. 2: Chemical structure of amoxicillin

Methotrexate is an anticancer agent which is a folic acid antagonist and it also contains glutamate tail having a carboxylate group which is an electron donor group and hence methotrexate is acidic in nature (fig. 3) [3].<smiles>CN(Cc1cnc2nc(N)nc(N)c2n1)c1ccc(C(=O)N[C@@H](CCC(=O)O)C(=O)O)cc1</smiles>

Fig. 3: Chemical structure of Methotrexate

The thiazide diuretics are weakly acidic with a benzothiadiazide 1 , 1-dioxide nucleus. The hydrogen atom at the $2-\mathrm{N}$ is the most acidic because of the electron-withdrawing effect of the neighboring sulfone group (fig. 4) [3].<smiles>NS(=O)(=O)c1cc2c(cc1Cl)N=CNS2(=O)=O</smiles>

Fig. 4: Chemical structure of Thiazide diuretics

Furosemide has a free carboxylic group in its structure due to which furosemide is strong acid than thiazide diuretics (fig. 5) [3].

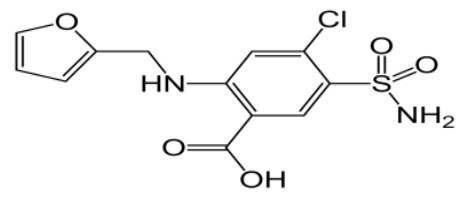

Fig. 5: Chemical structure of furosemide

Barbiturates are cyclic imides used as hypnotic and antiepileptic agents. All barbiturates are derived from barbituric acid which is pharmacologically inactive. Barbiturates contain nitrogen atoms but the lone pair of electrons is not available on nitrogen for the reaction with proton, so barbiturates are weak acid and not a base (fig. 6) [3].

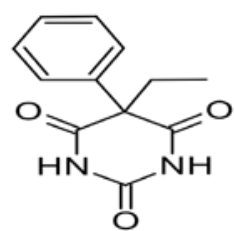

Fig. 6: Chemical structure of Phenobarbitone

\section{Method development and validation for acidic drugs Acyclovir}

For estimation of Acyclovir in bulk and tablet dosage form, new, rapid stability indicating method was developed and validated. For Acyclovir determination, Kromasil ODS C18 (4.6 mm x $250 \mathrm{~mm}, 5$ $\mu \mathrm{m})$ column was used and MeCN and acetate buffer $(\mathrm{pH} 4.5)$ were used as mobile phase in a proportion of 50:50, v/v. The detection was achieved at $253 \mathrm{~nm}$ and the run time was $1 \mathrm{ml} / \mathrm{min}$. The retention time was $2.47 \mathrm{~min}$ (fig. 7) [4].

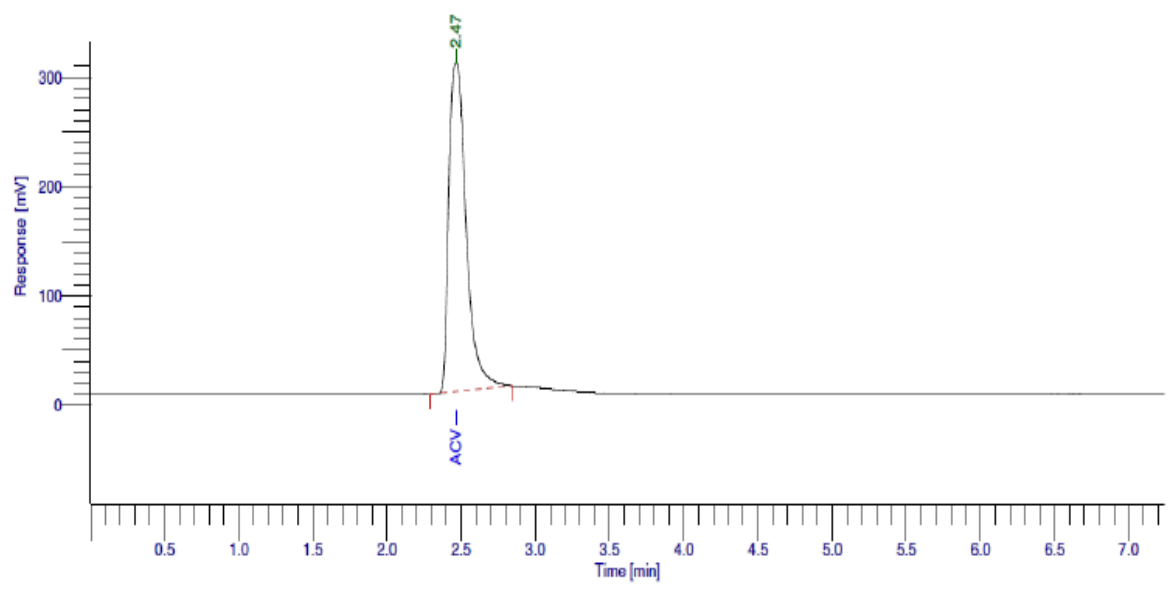

Fig. 7: Chromatogram of acyclovir 
Table 1: List of acidic drugs

\begin{tabular}{|c|c|c|c|c|}
\hline S. No. & Drugs & Structure & Category & pKa \\
\hline 1. & Acyclovir & & Antiviral agent & 2.27 and 9.25 \\
\hline 2. & Levodopa & & Antiparkinson agent & 2.3 \\
\hline & Amoxicillin & & Antibacterial agent & 2.62 \\
\hline 4. & Folic acid & & Hematologic agent & 2.7, 4.1 and 8.9 \\
\hline 5. & Salicylic acid & & Keratolytic agent, Antiseptic & 3.0 \\
\hline 6. & Furosemide & & Loop diuretics & 3.9 \\
\hline 7. & Ibuprofen & & NSAIDS & $4.2,5.2$ \\
\hline 8. & Methotrexate & & Anticancer & 4.8 \\
\hline 9. & Phenobarbital & & Sedative & 8.1 \\
\hline 10. & Phenytoin & & Antiepileptic & 8.3 \\
\hline
\end{tabular}

\section{Forced degradation study for acyclovir}

Acyclovir was subjected to stability indicating a study to check its stability in applied stress conditions. Acid, alkaline, oxidative and thermal hydrolysis stress conditions were applied to acyclovir.
From stability indicating studies, it showed that Acyclovir gets degraded in alkaline and oxidative hydrolysis. $9 \%$ drug gets degraded under the alkaline condition and $27 \%$ drug gets degraded under oxidative condition (fig. 8-9) [4].

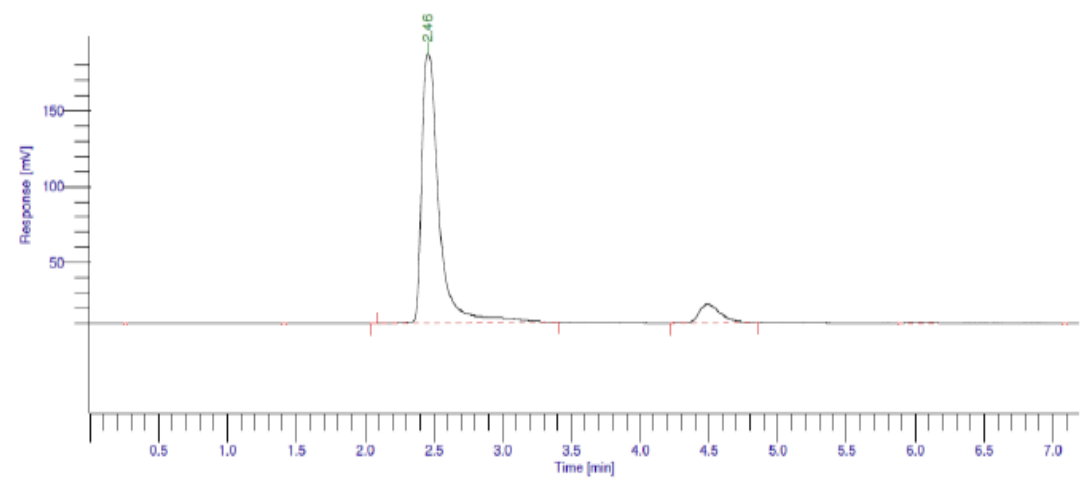

Fig. 8: Chromatogram of alkaline degradation of acyclovir 


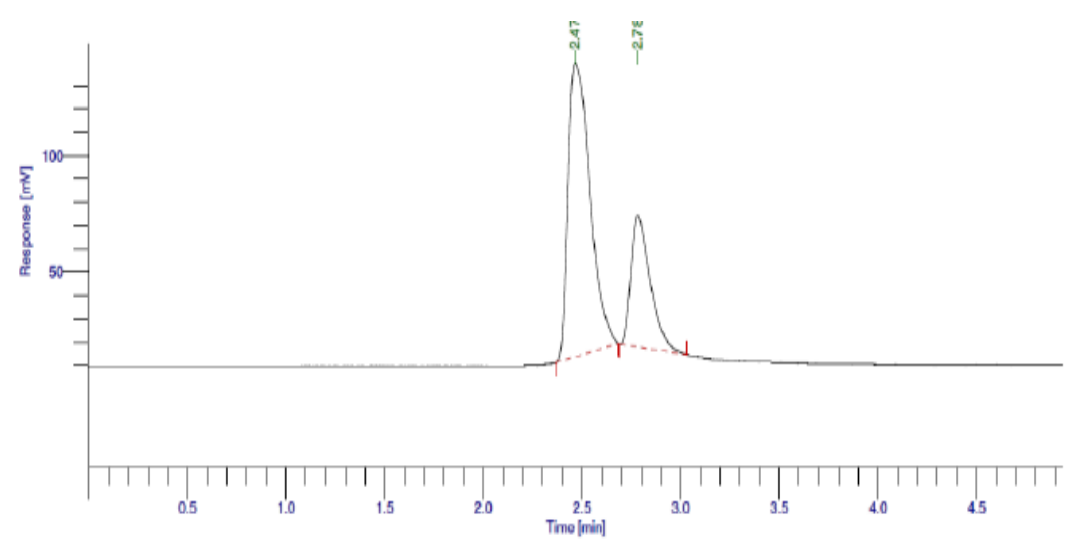

Fig. 9: Chromatogram of oxidative degradation of acyclovir

\section{Levodopa}

A new, simple isocratic, RP-HPLC stress indicating method was developed and validated for simultaneous estimation of Levodopa, Carbidopa and Entacapone in a combined dosage form. The separation was carried on Inertsil ODS C18 (4.6 $\mathrm{mm}$ x $250 \mathrm{~mm}, 5 \mu \mathrm{m})$ column and mobile phase consisted of water $(\mathrm{pH}$ adjusted by using potassium dihydrogen phosphate) and methanol in the ratio of $600: 400, \mathrm{v} / \mathrm{v}$. The flow rate was 1 $\mathrm{ml} / \mathrm{min}$ and column temperature was $30{ }^{\circ} \mathrm{C}$. The elution was detected at $257 \mathrm{~nm}$. The retention time for Levodopa, Carbidopa and Entacapone were $3.3 \mathrm{~min}, 4.1 \mathrm{~min}$, and $9.5 \mathrm{~min}$ respectively (fig. 10-11) [5].

\section{Forced degradation study for levodopa}

Marketed drug formulation consisting of Levodopa, Carbidopa and Entacapone were subjected to stress conditions of acidic, alkaline, thermal and peroxide degradation. In acidic stress condition Levodopa gets degraded (fig. 12-14) [5].

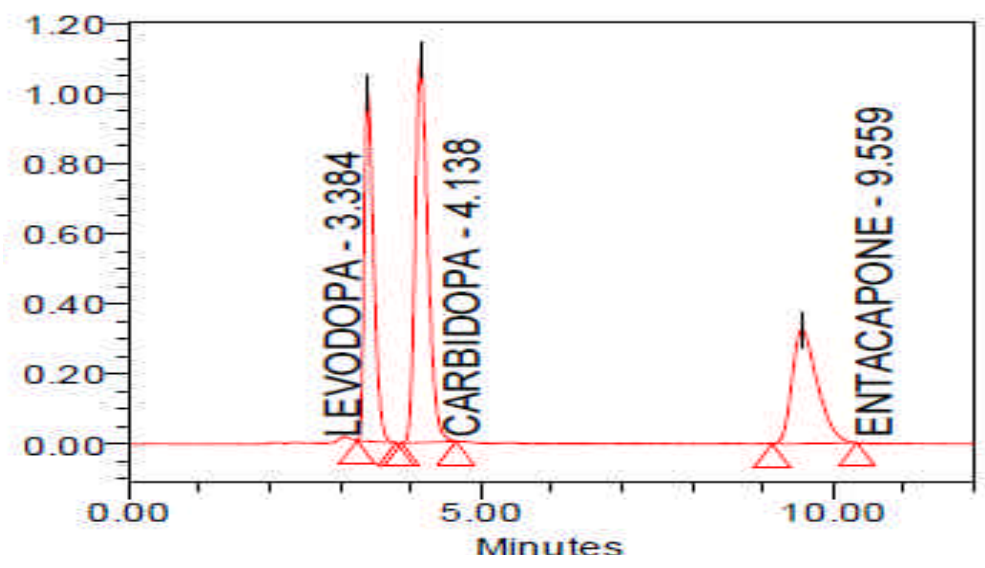

Fig. 10: Standard chromatogram of Levodopa, Carbidopa and Entacapone

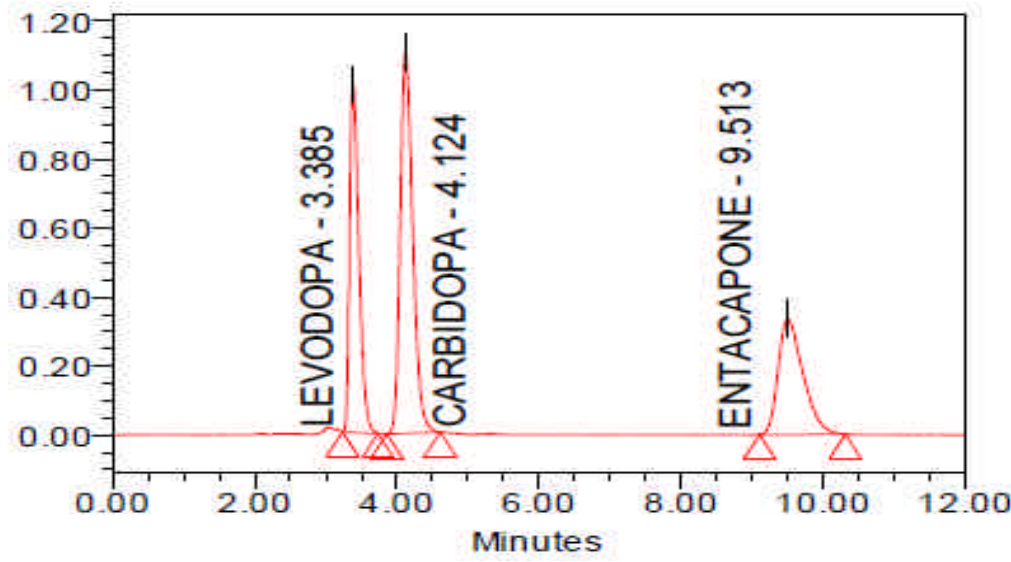

Fig. 11: Formulation chromatogram of levodopa, carbidopa and entacapone 


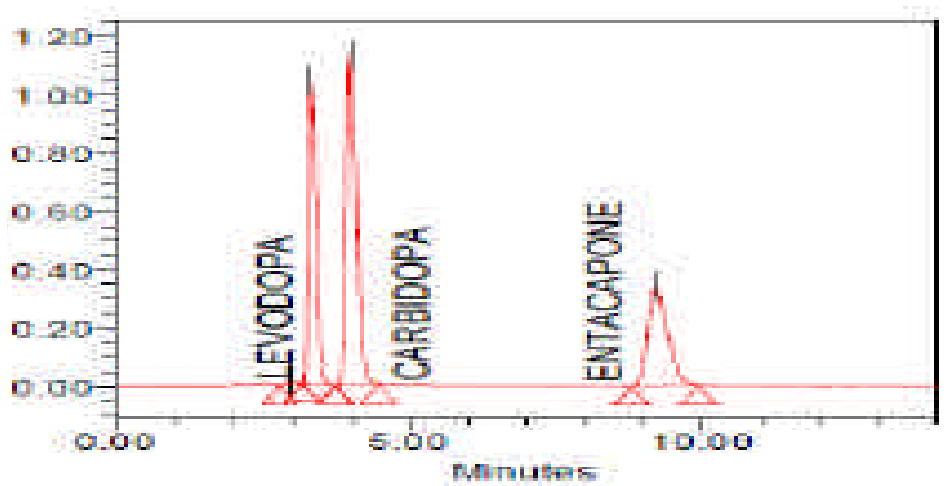

Fig. 12: Chromatogram of acid degradation of levodopa, carbidopa and entacapone

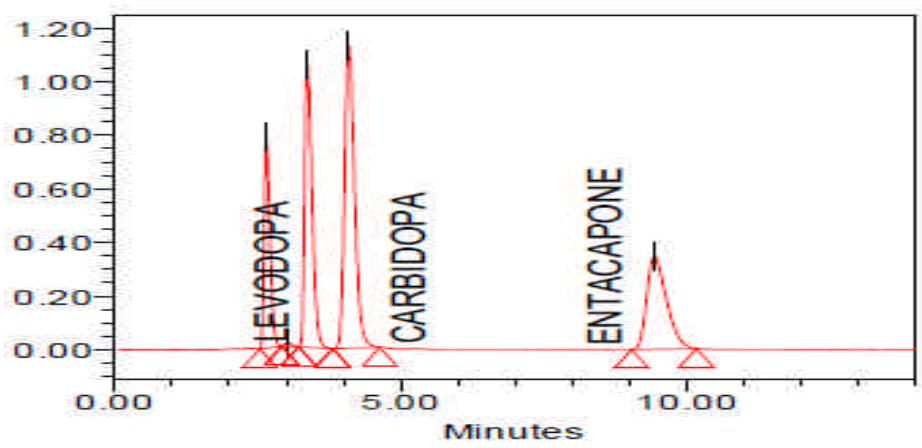

Fig. 13: Chromatogram of heat degradation of levodopa, carbidopa, and entacapone

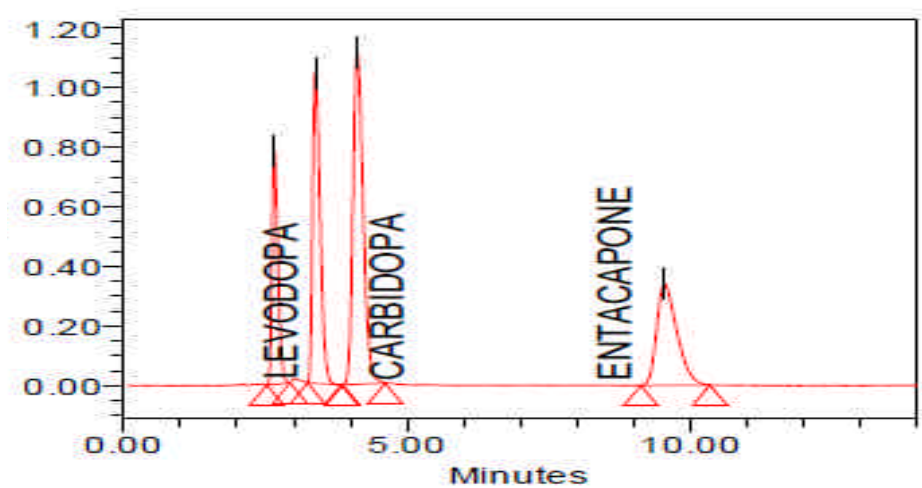

Fig. 14: Chromatogram of alkaline degradation of levodopa, carbidopa, and entacapone

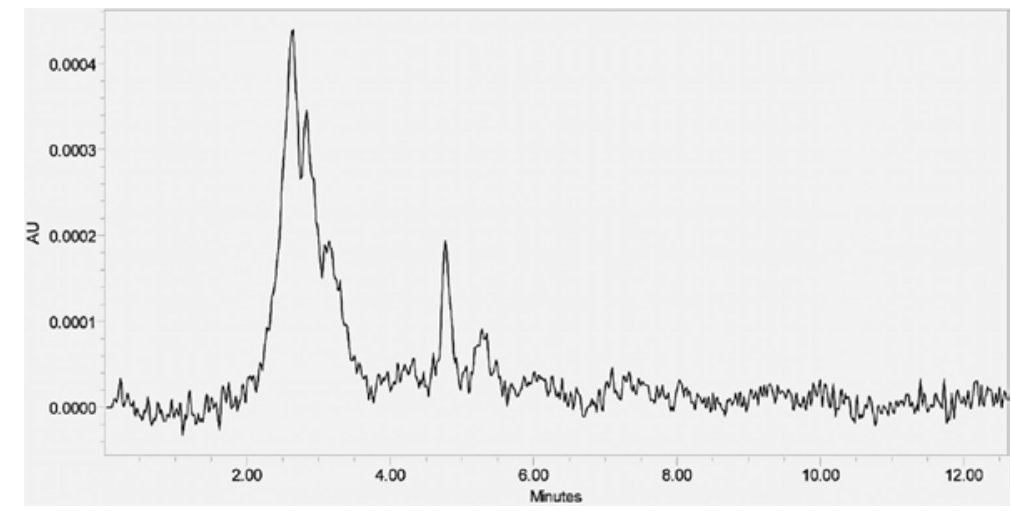

Fig. 15: Chromatogram of working blank solution 


\section{Amoxicillin}

A new, simple, rapid stability indicating RP-HPLC analytical method was developed for the simultaneous estimation of Flucloxacillin and Amoxicillin in bulk and pharmaceutical dosage form. The chromatographic separation for the two drugs was attained on a Thermosil C18 (4.6 $\mathrm{mm} \times 250 \mathrm{~mm}, 5 \mu \mathrm{m})$ column as the stationary phase at ambient temperature. The mobile phase composed of potassium dihydrogen phosphate buffer (adjusted to $\mathrm{pH} 3$ by using orthophosphoric acid) and Methanol (70:30\%, v/v) in isocratic mode at a flow of $1 \mathrm{ml} / \mathrm{min}$, and UV detection at $225 \mathrm{~nm}$. The run time was 8 min (fig. 15-16) [6].

\section{Forced degradation study for Amoxicillin}

Amoxicillin and flucloxacillin were subjected to stress conditions of acidic, basic, photolytic and thermal degradation. Amoxicillin degraded in photolytic and thermal conditions (fig. 17)-18) [6].

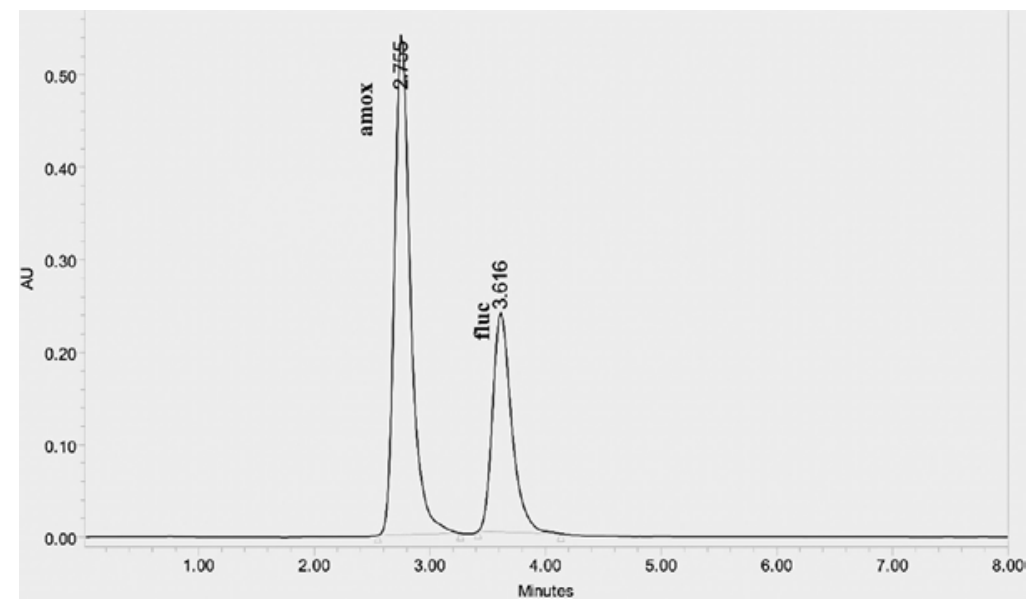

Fig. 16: Chromatogram of the formulation

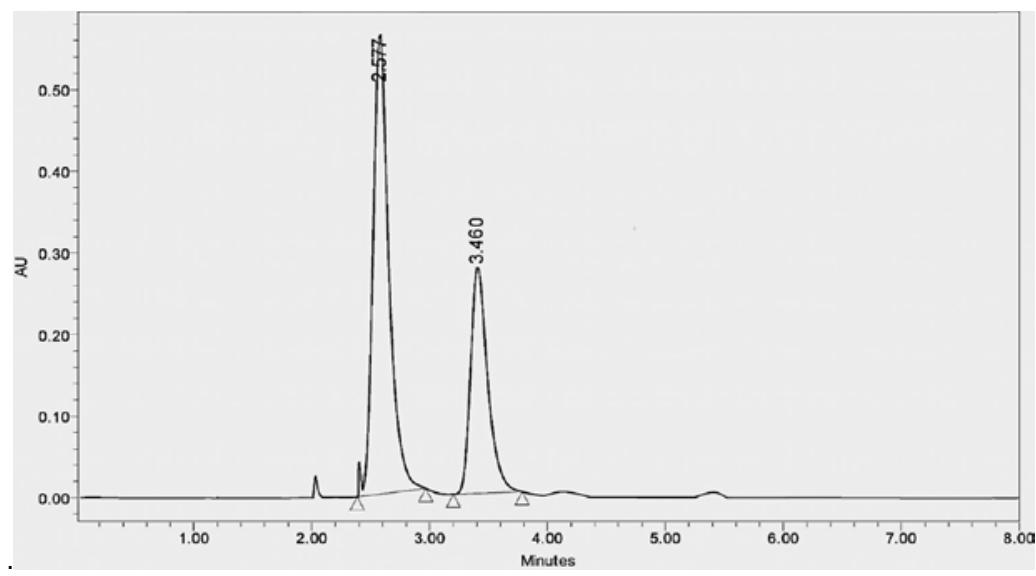

Fig. 17: Chromatogram of photolytic degradation study

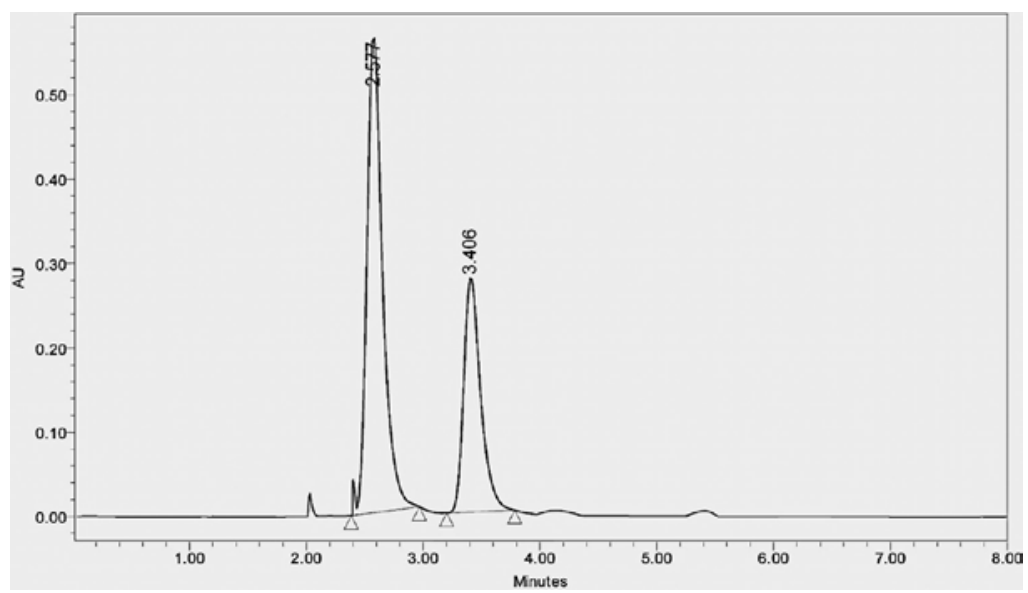

Fig. 18: Chromatogram of thermal degradation study 


\section{Folic acid}

An isocratic, selective, sensitive reverse-phase high-performance liquid chromatography was developed for the separation and quantification of Methotrexate and Folic acid on the tablet dosage form and further validated. The separation was eluted on
Phenomenx C18 column (4.6 mmx250 mm, $5 \mu \mathrm{m}$ ) as stationary phase using mobile phase mixture consisting of acetonitrile and orthophosphoric acid $(0.1 \%)$ in a ratio of $45: 55, \mathrm{v} / \mathrm{v}$. The flow rate was $1 \mathrm{ml} / \mathrm{min}$. The detection was carried out at $215 \mathrm{~nm}$. The retention times were $6.4 \mathrm{~min}$ for Methotrexate and $2.8 \mathrm{~min}$ for Folic acid (fig. 19) [7].

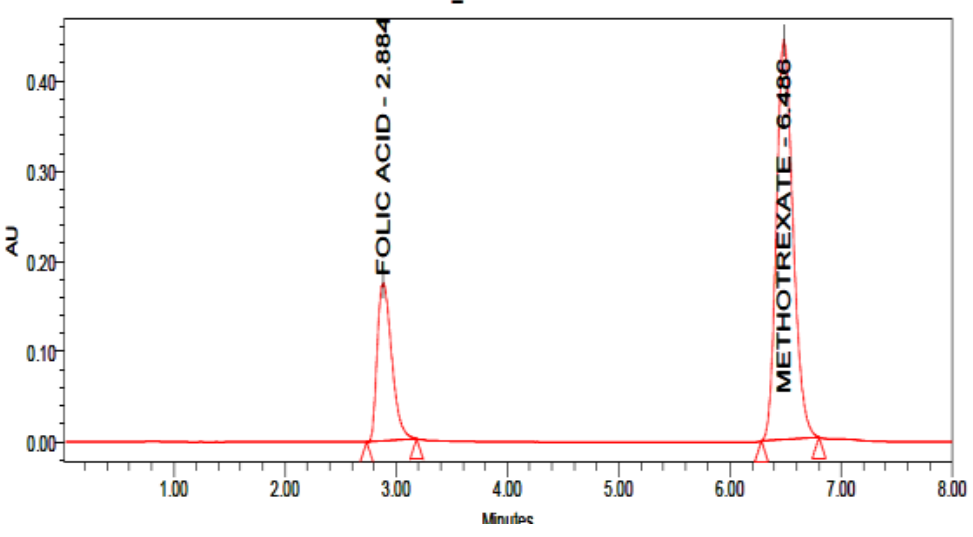

Fig. 19: Typical chromatogram of methotrexate and folic acid

\section{Forced degradation study for folic acid}

Marketed formulation of methotrexate and folic acid was subjected to stress conditions such as acidic, alkaline, oxidative, photolytic reduction, thermal and hydrolysis conditions. Methotrexate and Folic acid are stable under applied stress conditions like thermal, acidic, photolytic stress conditions. No degradants were observed under stability indicating the study of Methotrexate and Folic acid [7].

\section{Salicylic acid}

New RP-HPLC stability indicating method was developed and validated for the determination of Salicylic acid in a pharmaceutical dosage form. Shimadzu Prominance L20 AD HPLC equipped with
SPD 20A UV-Vis detector was used for the study of the analysis of salicylic acid in a pharmaceutical dosage form. RESTEX allure C18 column (4.6 mm x $12 \mathrm{~mm}, 3 \mu \mathrm{m})$ was used as the stationary phase. For isocratic elution, a mixture of water, methanol, and glacial acetic acid in a ratio of $65: 35: 1, \mathrm{v} / \mathrm{v}$ as mobile phase at a wavelength of 254 $\mathrm{nm}$. The flow rate was $1 \mathrm{ml} / \mathrm{min}$. The retention time was $7.65 \mathrm{~min}$ (fig. 20-21) [8].

\section{Forced degradation study for salicylic acid}

Salicylic acid was subjected to stress conditions like alkaline, acidic, neutral and photolytic stress conditions. No degradation was found in alkaline, acidic, photolytic and neutral stress conditions [8].

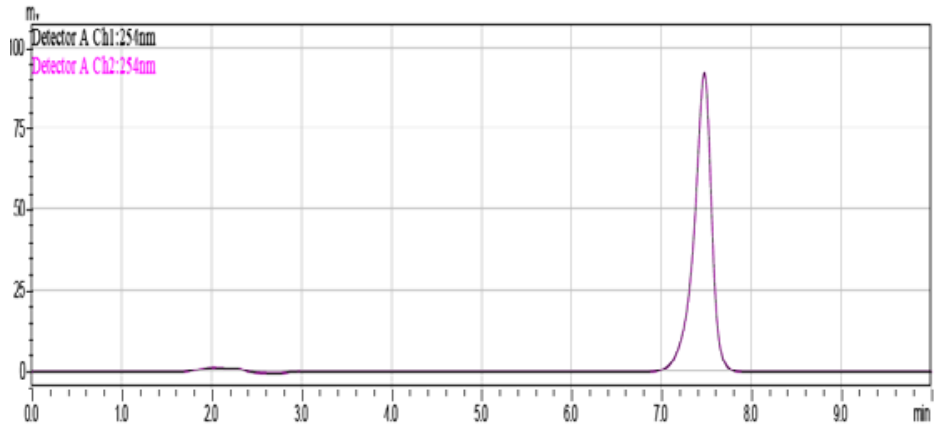

Fig. 20: Chromatogram of salicylic acid $(150 \mathrm{ug} / \mathrm{ml})$

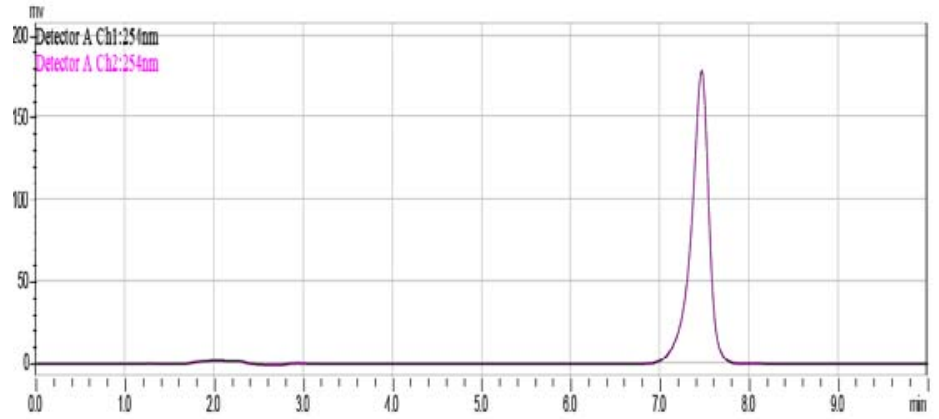

Fig. 21: Chromatogram of salicylic acid $(300 \mathrm{ug} / \mathrm{ml})$ 


\section{Furosemide}

A new, simple stability-indicating method and assay method was developed and validated for the simultaneous estimation of Spironolactone and Furosemide in a pharmaceutical solid dosage form. The separation was carried on SGE SS Wakosill II 5C8RS (4.6 $\mathrm{mm} \times 150 \mathrm{~mm}, 5 \mu \mathrm{m}$ ) column at ambient temperature. The mobile phase composed of acetonitrile and ammonium acetate, in a ratio of 50:50,v/v. The separation was detected at $245 \mathrm{~nm}$. The flow rate was $1 \mathrm{ml} / \mathrm{min}$. The retention time for Spironolactone and Furosemide was $2.9 \mathrm{~min}$ and $7.1 \mathrm{~min}$ respectively (fig. 22) [9].

\section{Forced degradation study for furosemide}

The marketed formulation of Spironolactone and Furosemide was subjected to acid, alkaline, thermal, oxidation and photolytic degradation. In acidic condition, 8.72\% drug degraded (fig. 23) [9].

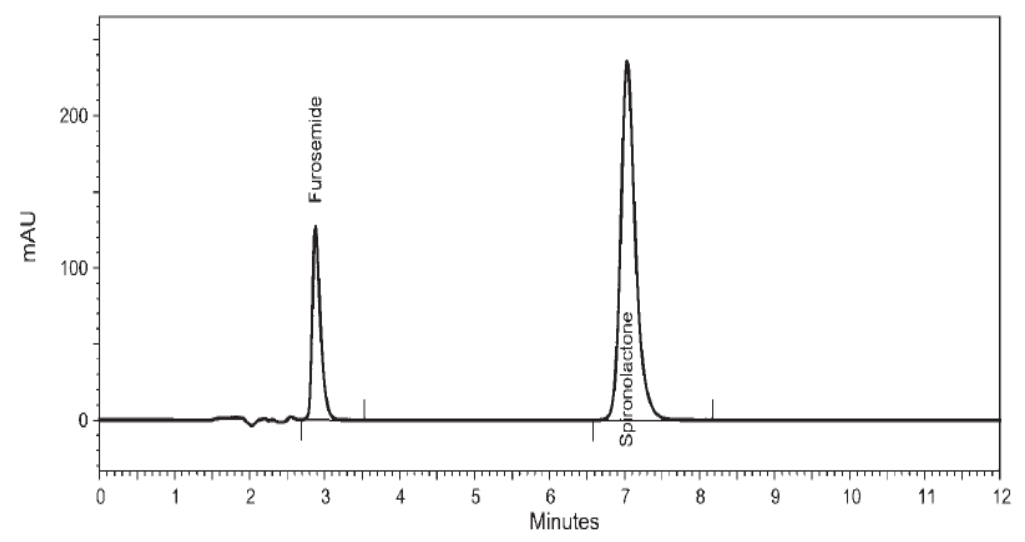

Fig. 22: Chromatogram of spironolactone and furosemide

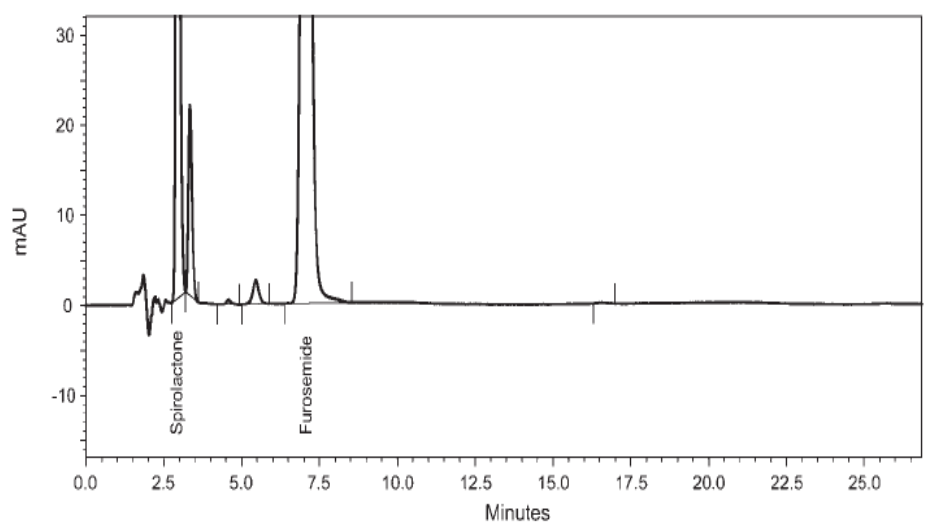

Fig. 23: Chromatogram of alkali degradation of spironolactone and furosemide

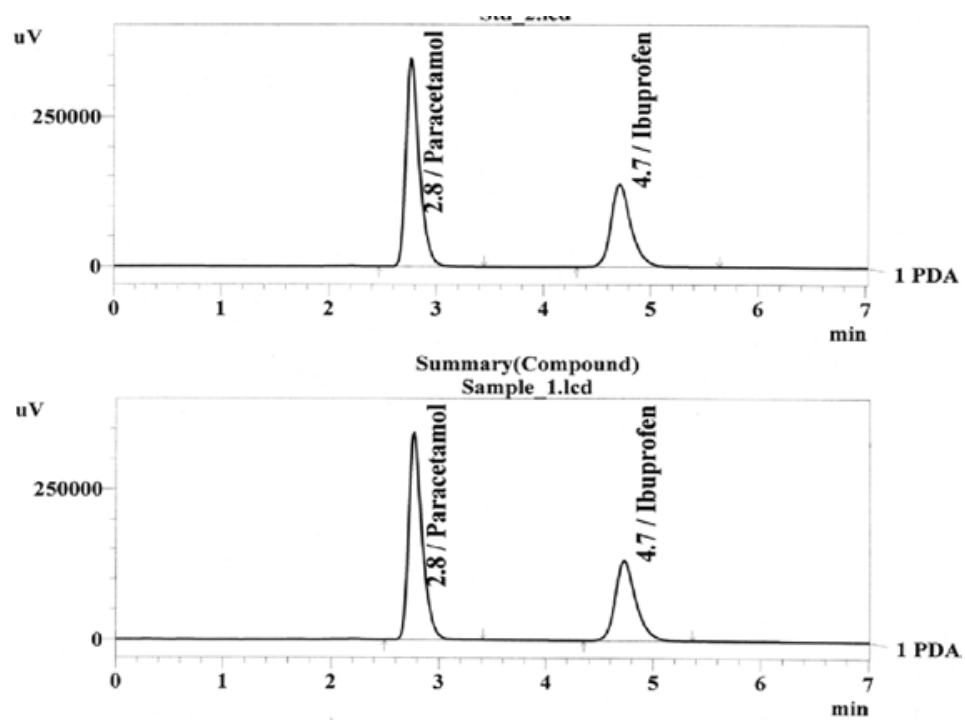

Fig. 24: Chromatograms of blank, standard, and sample 


\section{Ibuprofen}

A new, accurate, rapid and stability indicating method was developed and validated for the simultaneous estimation of Paracetamol and Ibuprofen in their combined dosage form. The elution was performed on C18 Phenomenex (4.6 mm x $250 \mathrm{~mm}, 5$ $\mu \mathrm{m})$ column and mobile phase contained phosphate buffer $(\mathrm{pH} 6.8)$ and acetonitrile in the ratio of $65: 35, \mathrm{v} / \mathrm{v}$. The flow rate was 0.7 $\mathrm{ml} / \mathrm{min}$. The elution was detected at $222 \mathrm{~nm}$. The retention time for
Paracetamol and Ibuprofen were $2.8 \mathrm{~min}$ and 4.7 min respectively (fig. 24) [10].

\section{Forced degradation study for Ibuprofen}

The standard mixture of Paracetamol and Ibuprofen was subjected to stability indicating studies such as acidic, basic, reduction and oxidative stress conditions. During stability studies, it was observed that Ibuprofen was stable in acidic condition but it showed degradation in strong basic condition within the limit (fig. 25) [10].

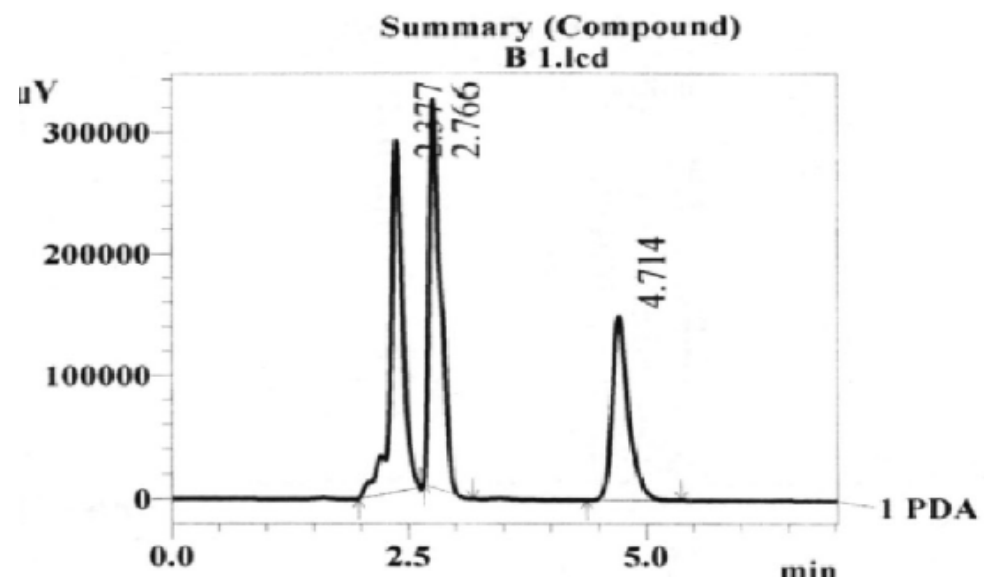

Fig. 25: Chromatogram of base degradation of Ibuprofen

\section{Methotrexate}

An isocratic, selective, sensitive reverse-phase high-performance liquid chromatography method has been developed for the separation and quantification of Methotrexate and Folic acid for the tablet dosage form and validated. The separation was eluted on
Phenomenx C18 column ( $4.6 \mathrm{~mm} \times 250 \mathrm{~mm}, 5 \mu \mathrm{m})$ as stationary phase using mobile phase mixture of acetonitrile and orthophosphoric acid $(0.1 \%)$ in a ratio of $45: 55, \mathrm{v} / \mathrm{v}$ at a flow rate of $1.0 \mathrm{ml} / \mathrm{min}$. The detection was carried out at $215 \mathrm{~nm}$. The retention times were $6.4 \mathrm{~min}$ for Methotrexate and $2.8 \mathrm{~min}$ for Folic acid (fig. 26) [11].

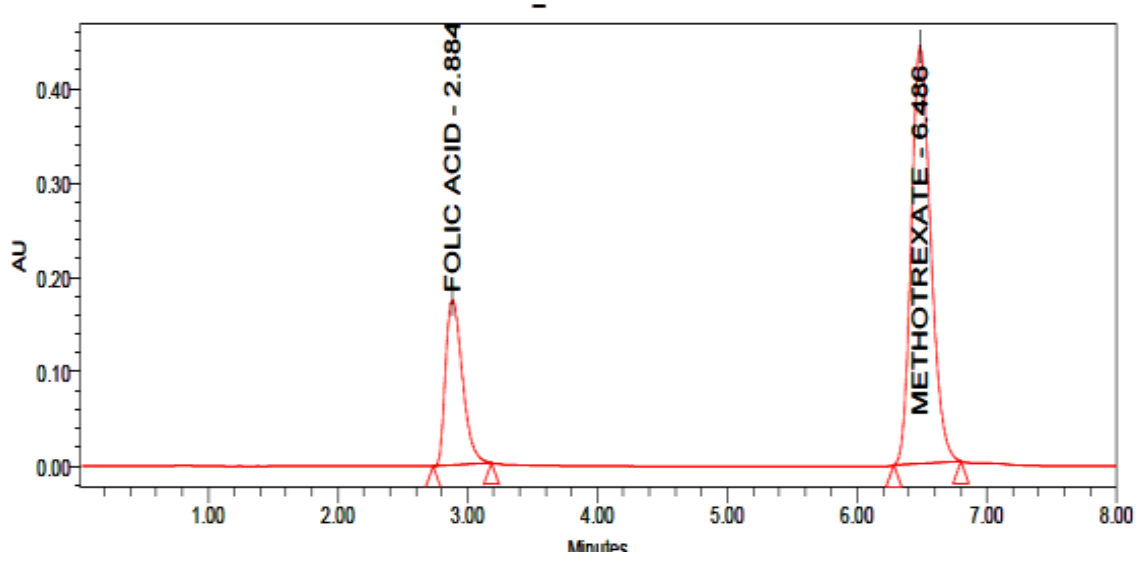

Fig. 26: Typical chromatogram of methotrexate and folic acid

\section{Forced degradation study for methotrexate}

Marketed drug formulation of Methotrexate and Folic acid were subjected to stress conditions such as acidic, alkaline, oxidative, photolytic, reduction, thermal and hydrolysis conditions. The methotrexate and folic acid were stable under applied stress conditions like thermal, acidic, photolytic stress conditions. No degradants were observed under stability indicating studied of Methotrexate and Folic acid [11].

\section{Phenobarbitone}

A new simple RP-HPLC stability indicating method was developed and validated for quantification of Phenobarbitone in a pharmaceutical dosage form. The elution was carried out on C18 R $(4.6 \mathrm{~mm} \times 250 \mathrm{~mm}, 5 \mu \mathrm{m})$ column and acetonitrile and methanol used as mobile phase in a ratio of $65: 35, \mathrm{v} / \mathrm{v}$ in isocratic mode. The detection was done at $237 \mathrm{~nm}$. The retention time was $4.78 \mathrm{~min}$ (fig. 27) [12].

\section{Forced degradation study for phenobarbitone}

The working standard of Phenobarbitone was subjected to various stress conditions such as acid, base, oxidation, thermal, dry heat and photolytic stress conditions. From forced degradation studies it was found that Phenobarbitone gets degraded in acid, base, oxidative and thermal stress conditions (fig. 28-31) [12]. 


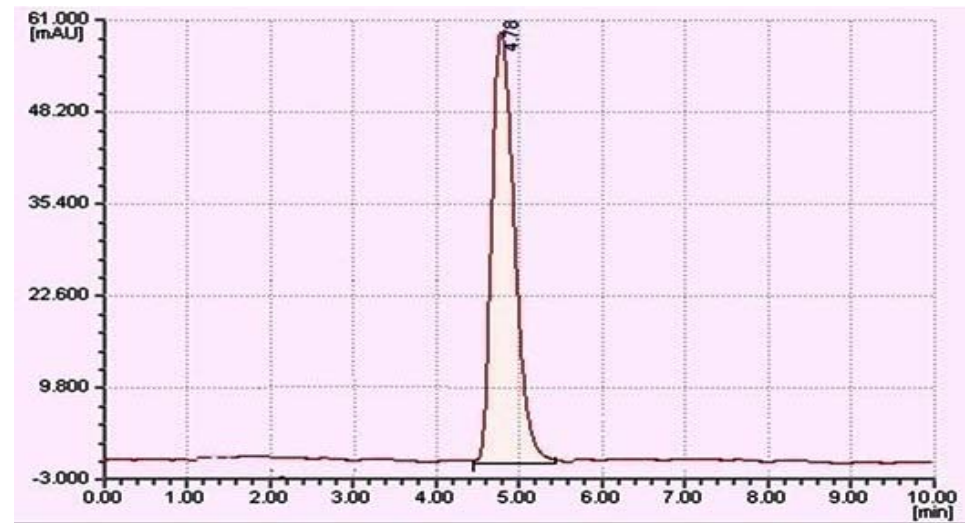

Fig. 27: Chromatogram of phenobarbitone

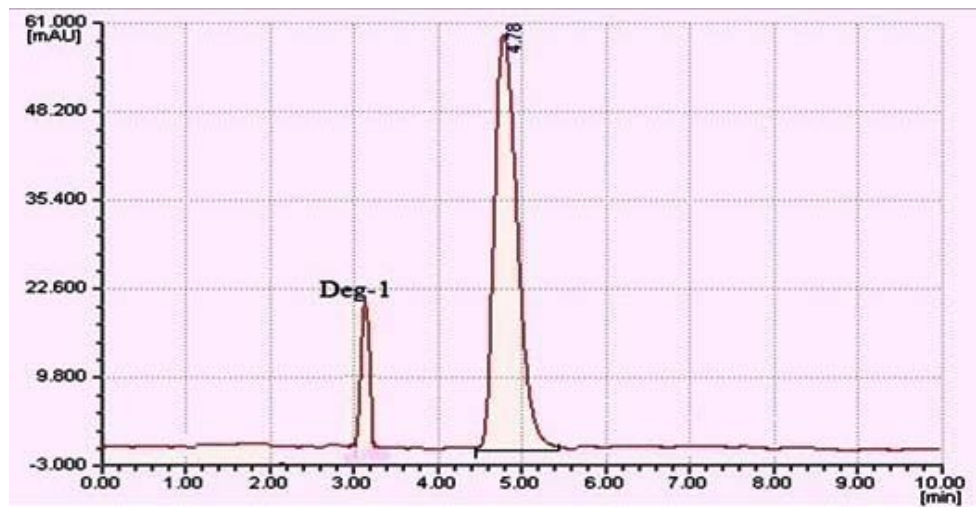

Fig. 28: Chromatogram of phenobarbitone after acid hydrolysis

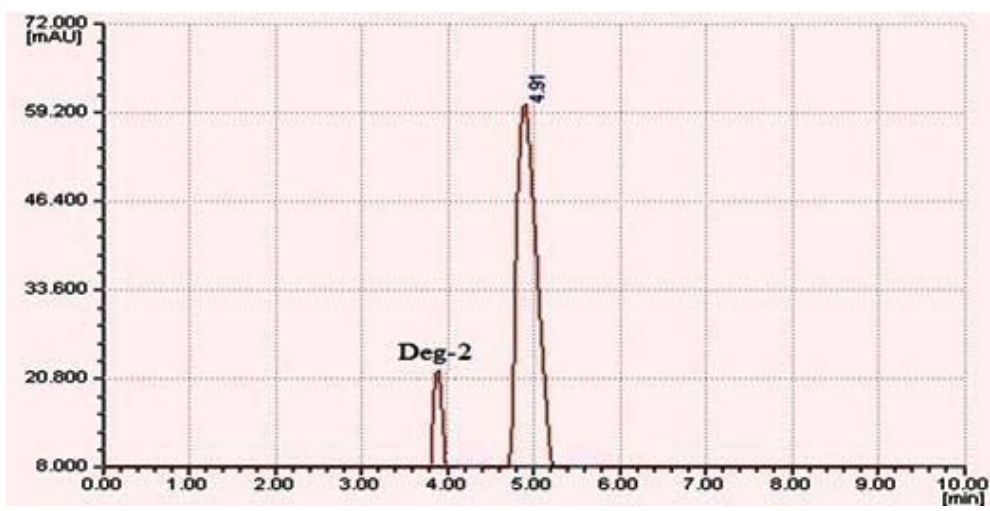

Fig. 29: Chromatogram of phenobarbitone after alkali hydrolysis

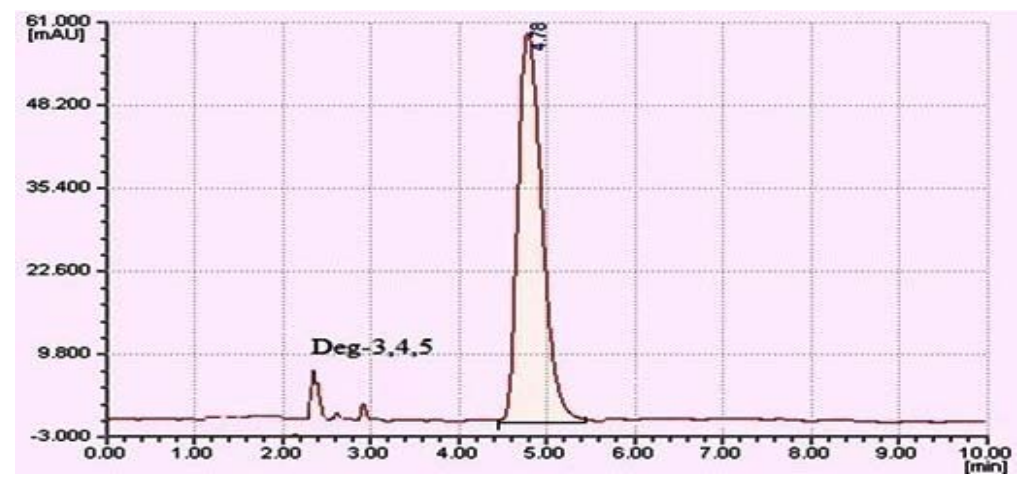

Fig. 30: Chromatogram of phenobarbitone after oxidative hydrolysis 


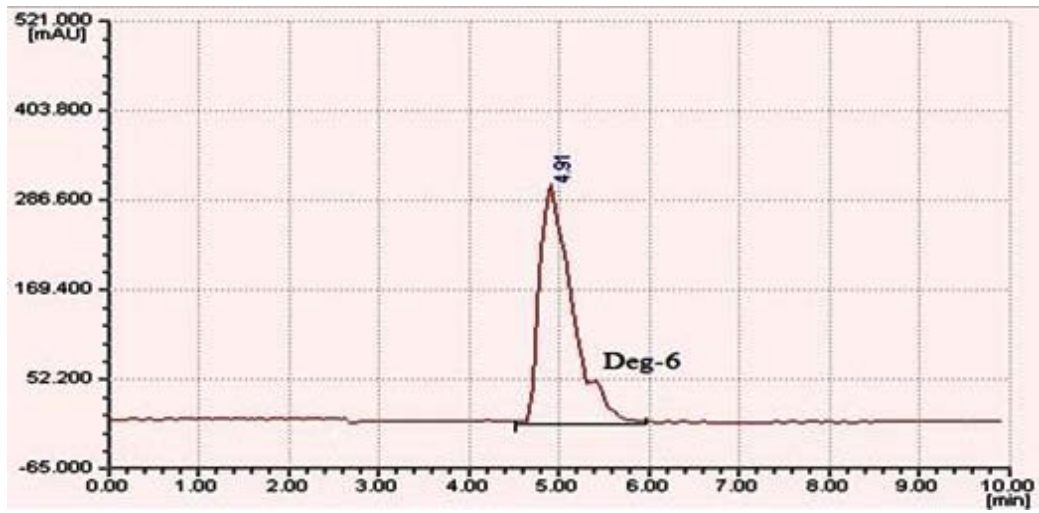

Fig. 31: Chromatogram of phenobarbitone after dry heat degradation

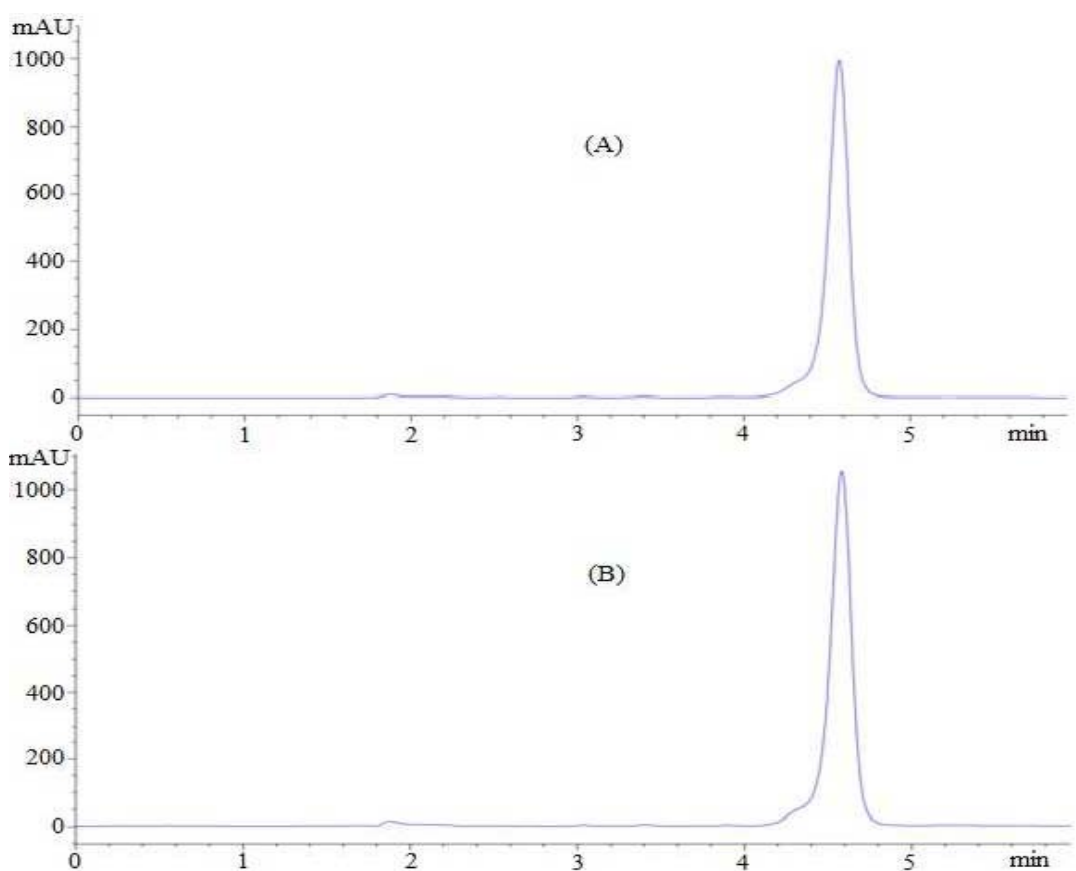

Fig. 32: Typical chromatogram of standard phenytoin (A) and Phenytoin from formulation (B)

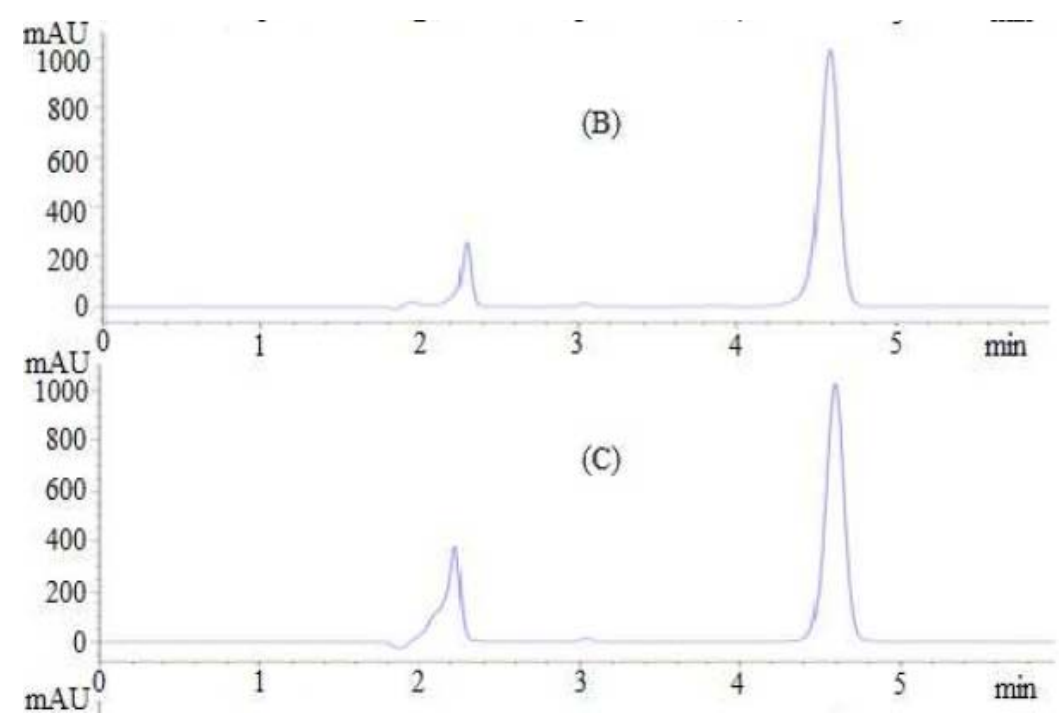

Fig. 33: Chromatogram of oxidative degradation of phenytoin (b), and base degradation (c) 


\section{Phenytoin}

A simple, new and stability indicating method was developed and validated for the estimation of Phenytoin in a pharmaceutical dosage form. The separation was achieved by using Zorbax C18 (4.6 mm x $250 \mathrm{~mm}, 5 \mu \mathrm{m}$ ) column at ambient temperature and mobile phase contained acetonitrile and water in a ratio of $50: 50 \%, \mathrm{v} / \mathrm{v}$ in isocratic mode. The detection was done at $200 \mathrm{~nm}$ and the flow rate was $1 \mathrm{ml} / \mathrm{min}$ (fig. 32) [13].

\section{Forced degradation study for phenytoin}

Phenytoin subjected to stress conditions such as acid, base, oxidative and photolytic condition and from forced degradation studies it showed that Phenytoin gets degraded in oxidative and basic stress conditions (fig. 33) [13].

\section{CONCLUSION}

High-Performance Liquid Chromatography has a wide variety of uses in many fields such as analysis, separation, and identification of pharmaceutical drug, impurity and biological samples. This article gives an overview of analysis and stability indicating method development and validation of acidic drugs.

\section{AUTHORS CONTRIBUTIONS}

All the author have contributed equally

\section{CONFLICT OF INTERESTS}

Declare none

\section{REFERENCES}

1. Thammana M. A review on high-performance liquid chromatography (HPLC). Res Rev: J Pharm Anal 2016;5:22-8.

2. Malviya R, Bansal V, Pal OP, Sharma PK. High-performance liquid chromatography: a short review. JGPT 2010;2:22-6.

3. Kazakevich YV. HPLC method development for pharmaceuticals. Sep Sci Technol 2007;8:13-44.

4. Bhardwaj SK, Dwivedi K, Agarwal DD, Analytical S. A review on analytical method development and validation. Int J Appl Pharm 2018;10:8-15.

5. Azim Md Sabir, Mitra Moloy, Bhasin Parminder S. HPLC method development and validation. Int Res J Pharm 2015;5:76-81.

6. Jimidar MI, De Smet M. HPLC method development for pharmaceuticals; 2007.

7. Snyder LR, Glajch JL, Kirkland JJ. Practical HPLC method development. Vol. 2nd ed.; 1997.
8. Foey's Principles of Medicinal Chemistry by Thomas L Lemke, David A Williams, Victoria F Roche, S William Zito. $7^{\text {th }}$ edition; 2008. p. 1377.

9. Musmade A, Jain H, Prajapati R. Development and validation of stability indicating RP-HPLC method for analysis of acylovir in API and in the pharmaceutical dosage form. World J Pharm Res 2015;4:1043-52.

10. V Rama Krishna, K Bala Murali Krishna, B Hari babu Development and validation of liquid chromatographic method for simultaneous estimation of levodopa, carbidopa and entacapone in combined dosage form. J Pharm Res 2014;8:281-8.

11. Sarif Niroush Konari, Jane T Jacob. Stability indicating LCanalytical method development and validation for the simultaneous estimation of flucloxacillin and amoxicillin in the pharmaceutical dosage form. J Taibah University Sci 2015;9:167-76.

12. Jogi K, Mandava Rao MB, Rundraraju Ramesh Raju. Development and validation stability indicating RP-HPLC method for the estimation of methotrexate and folic acid in bulk and tablet dosage form. Int J Eng Technol Sci Res 2016;10:2394-3386.

13. Talath S, Dhaneshwer S. Validated stability-indicating RP-HPLC method for the determination of salicylic acid. Am J PharmTech Res 2017;7:232-49.

14. Ram VR, Dave PN, Joshi HS. Development and validation of stability indicating HPLC assay method for simultaneous determination of spironolactone and furosemide in tablet formulation. J Chromatogr Sci 2012;50;721-6.

15. Md Sarowar Jahan, Md Jahirul Islam, Rehana Begum, Kayesh $\mathrm{R}$, Rahman A. A study of method development validation and forced degradation for simultaneous quantification of paracetamol and ibuprofen in pharmaceutical dosage form by RP-HPLC method. Anal Chem Insights 2014;9:75-81.

16. Jogi K, Rao MB, Rundraraju Ramesh Raju RR. Development and validation stability indicating RP-HPLC method for the estimation of methotrexate and folic acid in bulk and tablet dosage form. Int J Eng Technol Sci Res 2016;3:2394-3386.

17. Mhatre PR, Gatkal SH, Chopade VV, Chaoudhari PD. Development and validation of stability indicating HPLC assay method for determination of phenobarbitone in bulk drug and tablet formulation. Int J Pharm Sci Res 2013;4:1820-6.

18. Siew Yong Teo, Michael J Rathbone, Allan GA Coombes, Siang Yin Lee, Seng Neon Gan. Development and validation of a stability-indicating isocratic reverse phase-liquid chromatography assay for determination of phenytoin in bulk and pharmaceutical formulations, Int J Pharm Pharm Sci 2015;7:258-63. 